asthma) reported that their asthma was caused, or made worse, by their work. $17.8 \%$ reported wheeze in the last 12 months.

Grouping relevant exposures, 117 of the 123 participants reported in decreasing order of proportion, the following agents as being responsible for worsening of their asthma; organic dusts $(\mathrm{n}=73,59 \%)$, unspecified dust $(\mathrm{n}=12,10 \%)$, mixed exposures $(\mathrm{n}=12,10 \%)$, any mention of chemical $(n=9,7 \%)$, physical work environment, e.g. temperature, exercise $(n=7,6 \%)$, other, e.g. irritant, fumes ( $\mathrm{n}=4,3 \%)$.

This large study of pesticide applicators has confirmed a prevalence of $11.4 \%$ for doctor-diagnosed asthma. Selfreported exposures thought by workers to aggravate their asthma were predominantly organic in nature, although a smaller proportion identified chemicals as aggravants. Workplace based preventative strategies in this sector should address all potential inhaled hazards and their associated risks to respiratory health.

\section{O2A.2 PESTICIDES AND RESPIRATORY HEALTH; THE GB BASED PIPAH STUDY}

'David Fishwick*, ${ }^{1}$ Anne-Helen Harding, ${ }^{1}$ David Fox, ${ }^{1}$ Chen Yiqun, ${ }^{2}$ Neil Pearce, ${ }^{1}$ Gillian Frost. ${ }^{1}$ HSE GB and NHS, Sheffield, UK; ${ }^{2}$ London School of Hygiene and Tropical Medicine, London, UK

\subsection{6/OEM-2019-EPI.34}

We administered a cross sectional respiratory questionnaire in January to 4814 PIPAH (Prospective Investigation of Pesticide Applicators' Health) participants. Of the 2562 respondents (53\% response) with a median age of 60.2 years, $97.4 \%$ were male and 34.1\% ever smoked.

The prevalence of ever doctor diagnosed conditions was $11.4 \%$ for asthma, $1.29 \%$ for COPD, $0.9 \%$ for chronic bronchitis and $0.4 \%$ for farmer's lung.

Self-reported symptoms, however, were more prevalent. Nasal allergies were reported by $21.4 \%$, coughing in winter (possibly signifying chronic bronchitis) by $13.7 \%$, chest tightness or difficulty in breathing by $12.9 \%$ and trouble in breathing by $9 \%$. The majority $(n=1806,86 \%)$ had mixed, loaded handled or applied pesticides in the last 12 months, in a range of work areas.

For those respondents actively using pesticides, the association between respiratory health and pesticide use was investigated using logistic regression. Doctor diagnosed; none of the doctor diagnosed conditions were statistically associated with (binary) pesticide use in the last 12 months. Doctor diagnosed asthma was only associated with age (OR 0.987, $\mathrm{p}=0.024)$ and ever smoking (OR 1.47, $\mathrm{p}=0.004)$.

Self-reported; self-reported nasal allergies $(\mathrm{OR}=1.81)$, chest tightness $(\mathrm{OR}=2.18)$ and trouble breathing $(\mathrm{OR}=2.68)$ were associated with 'golf courses, bowling greens, sports grounds' work, cough $(\mathrm{OR}=1.91)$ with forestry and cough $(\mathrm{OR}=1.4)$ and wheeze $(\mathrm{OR}=1.31)$ with grain store work. After adjustment for age, self-reported nasal allergy was significantly inversely associated with pesticide use (OR $0.72, p=0.03$ ), although no significant associations with pesticide use were identified for other selfreported symptoms.

This study has identified low levels of doctor diagnosed ill health in this group, in contrast to more prevalent self- reported symptoms; suggesting the possibility of underdiagnosis of respiratory ill health. Forestry and grassexposed areas were associated with nasal allergies and cough. Pesticide use specifically was only associated with nasal allergies.

\section{O2A.3 INCREASED RISK OF CENTRAL NERVOUS SYSTEM TUMORS WITH CARBAMATE INSECTICIDE USE IN THE PROSPECTIVE COHORT AGRICAN}

${ }^{1}$ Clément Piel* ${ }^{1,2}$ Camille Pouchieu, 'Lucile Migault, ${ }^{1}$ Beatrix Béziat, 3,4,5 Mathilde Boulanger, ${ }^{1}$ Mathilde Bureau, ${ }^{1,6}$ Camille Carles, ${ }^{1,2}$ Anne Grüber, 3,4,5Yannick Lecluse, 'Virginie Rondeau, ${ }^{1}$ Xavier Schwall, ${ }^{3,4,5}$ Séverine Tual, ${ }^{7}$ the AGRICAN group, ${ }^{3,4,5}$ Pierre Lebailly, ${ }^{1,2,6}$ Isabelle Baldi. ' Epicene Team, Isped, U1219 Inserm, Bordeaux Population Health Research Center, University of Bordeaux, Bordeaux, France; ${ }^{2}$ Registre des tumeurs primitives du système nerveux central de la Gironde, ISPED, Centre INSERM U1219, Bordeaux Population Health Research Center, University of Bordeaux, Bordeaux, France; ${ }^{3}$ INSERM, U1086 Anticipe Axe Cancers et Préventions, Caen, France; ${ }^{4}$ Université de Caen Normandie, Caen, France; ${ }^{5}$ Centre de Lutte Contre le Cancer François Baclesse, Caen, France; ${ }^{6} \mathrm{CHU}$ de Bordeaux, Service de Médecine du Travail et Pathologies Professionnelles, Bordeaux, France; ${ }^{7}$ Arveux P (Registre des Cancers du Sein et Cancers Gynécologiques de Côte d'Or), Bara S (Registre Général des Cancers de la Manche), Bouvier AM (Registre Bourguignon des cancers Digestifs), Busquet T (MSA Gironde), Colonna M (Registre Général des Cancers de I'Isère), Coureau G (Registre Général des Cancers de la Gironde), Delanoé M (MSA Midi Pyrénées Nord), Grosclaude P (Registre Général des Cancers du Tarn), Guizard AV (Registre Général des Tumeurs du Calvados), Herbrecht P (MSA Alsace), Laplante JJ (MSA Franche Comté), Lapotre-Ledoux B (Registre Général des Cancers de la Somme), Launoy $G$ (Registre des tumeurs digestives du Calvados), Lenoir D (MSA Bourgogne), Marrer E (Registre Général des cancers du Haut-Rhin), Marcotullio E (Caisse Centrale de la MSA), Maynadié M (Registre des Hémopathies Malignes Côte d'Or), Molinié F (Registre Général de la Loire-Atlantique et Vendée), Monnereau A (Registre des Hémopathies Malignes de la Gironde), Paumier A (MSA Picardie), Pouzet P (MSA Côtes Normandes), Thibaudier JM (MSA Alpes du Nord), Troussard X (Registre Régional des Hémopathies Malignes de Basse Normandie), Velten M (Registre Général des Cancers du Bas-Rhin), Wavelet E (MSA Loire Atlantique-Vendée), Woronoff AS (Registre général des tumeurs du Doubs)

\subsection{6/OEM-2019-EPI.35}

Background Pesticide exposures are suspected to be implicated in the excess of Central Nervous System (CNS) tumors observed in farmers, but evidence concerning individual pesticides remains limited. Carbamate insecticides, used on a wide range of crops, have shown evidence of carcinogenicity in some experimental studies. In the cohort AGRICAN (AGRIculture and CANcer), we assessed the associations between potential exposures to carbamate insecticides and the incidence of CNS tumors, overall and by histological subtype.

Methods AGRICAN enrolled 181842 participants involved in agriculture. Incident CNS tumors were identified by linkage with cancer registries from enrolment (2005-2007) until 2013. Carbamate exposure was assessed by combining information on lifetime periods of pesticide use on crop or livestock and the French crop-exposure matrix PESTIMAT, individually for each of the 19 carbamate insecticides registered in France since 1950. Associations were estimated using proportional hazards models with age as the underlying timescale, adjusting for gender, educational level and smoking.

Results During a 6.9 year average follow-up, 381 incident cases of CNS tumors occurred, including 164 gliomas and 134 meningiomas. Analyses showed increased risks of CNS tumors with overall exposure to carbamate insecticides and linear trends with duration of use of each carbamate. Considering tumor subtypes, hazard ratios for gliomas ranged from 1.18 for thiofanox to 4.60 for 